\title{
A MÁSCARA REVELADORA DA PSEUDOTRADUÇÃO ${ }^{1}$
}

\section{Annie Alvarenga Hyldgaard Nielsen}

Num trabalho intitulado "A case of pseudotranslation in the Portuguese literary system” (2005), a doutora em literatura portuguesa Maria Lin de Sousa Moniz compara o pseudônimo na literatura a uma máscara capaz de ocultar a verdadeira identidade do autor, e a pseudotradução, ou tradução fictícia, a uma máscara dupla, visto que permite ao escritor se esconder tanto atrás do pseudônimo como da tradução. Trata-se de uma metáfora pertinente. No entanto, quando se analisam os motivos que levam alguém a recorrer à pseudotradução, bem como o modo como a obra é recebida pelo público, percebe-se que essa "máscara” pode, ao contrário, revelar muito mais do que encobrir. Uma vez identificada, permite saber mais sobre o autor, sobre as forças políticas e ideológicas às quais estava sujeito e sobre o grau de receptividade da sua cultura a novos estilos literários. A obtenção de tais informações é apenas um dos motivos que levaram pesquisadores a reconhecerem na pseudotradução um objeto de estudo legítimo.

O estudo desse fenômeno foi iniciado pelos teóricos da linha descritivista dos Estudos da Tradução (Descriptive Translation Studies - DTS), que rejeitam a abordagem normativa e partem sempre do produto, ou seja, do texto-meta, para tecer suas análises. Dentre os nomes que se dedicaram ao tema despontam os da inglesa Susan Bassnett, da Universidade de Warwick, e, sobretudo, o do israelense Gideon Toury, da Universidade de Tel Aviv. Toury definiu as pseudotraduções como "textosmetas considerados traduções pela cultura de chegada, embora não seja possível identificar nenhum texto-fonte genuíno para tais escritos” (Toury, apud Shuttleworth, 1997: 135). ${ }^{2}$

Obviamente, as pseudotraduções só podem ser classificadas como tais a partir do momento em que se desvenda a fraude. De acordo com Toury, elas têm relevância para os estudos da tradução por dois motivos básicos. Em primeiro lugar, proporcionam um

\footnotetext{
${ }^{1}$ Este trabalho é parte da dissertação de mestrado intitulada A face oculta de Pagu: um caso de pseudotradução no Brasil do século XX, defendida junto ao Programa de Pós-Graduação em Letras Estudos da Linguagem da PUC-Rio, em 2007.

${ }^{2}$ Todas as citações de referências em inglês foram traduzidas pela autora.
} 
rico panorama das principais características usadas nos textos traduzidos, visto que seus produtores utilizam os aspectos lingüísticos e textuais mais encontrados em traduções verdadeiras. Afinal, uma obra só circulará como tradução sem levantar suspeita se for suficientemente crível e persuasiva. Em segundo lugar, as traduções fictícias servem para introduzir inovações nos sistemas literários, principalmente naqueles resistentes a padrões que fujam das normas e dos modelos consagrados (Shuttleworth, 1997: 135). $\mathrm{Na}$ verdade, afirma o teórico israelense, elas constituem uma das poucas formas que permitem ao autor ousar sem risco de desencadear reações contrárias. Assim, escritores cuja obra apresente traços muito próprios sentem-se livres para experimentarem outras fórmulas, como foi o caso de The castle of Otranto (1765), obra do inglês Horace Walpole responsável pela inauguração do romance gótico na Europa, que, no ano do seu lançamento, circulou como uma tradução de um original italiano. O mesmo se aplica a Gengaeldens Veje (1944), de Karen Blixen. Escrito durante a ocupação alemã da Dinamarca, esse romance introspectivo e alegórico sobre o nazismo - tão diferente de seus contos - foi apresentado como obra de Pierre Andrézel, em tradução do francês para o dinamarquês de Clara Svendesen (Toury, 1995: 42).

No livro Descriptive Translation Studies and beyond (1995), Gideon Toury lista outras funções da pseudotradução além das de proporcionar uma visão dos principais aspectos utilizados em traduções e de viabilizar a introdução de novos padrões literários. No entender do teórico, apresentar um texto original como tradução muitas vezes significa uma tentativa de conferir-lhe o mesmo prestígio atribuído à língua e à cultura da qual ele supostamente se originou. Tal fenômeno ocorreu de forma muito clara na literatura russa do século XIX, quando havia uma enorme demanda por obras semelhantes aos romances ingleses, muito admirados na época. Diante dessa valorização, vários títulos foram produzidos e falsamente apresentados ao público como traduções de romancistas ingleses, sobretudo como se fossem de Ann Radcliffe, apontada como a mais emblemática representante do romance inglês pela cultura receptora (Masanov, apud Toury, 1995: 43).

Outro propósito das pseudotraduções apontado por Toury seria o de contribuir para a consolidação de formas não canônicas e claramente associadas a produções estrangeiras. A literatura hebraica da década de 1960 ilustra bem essa tese. Vários romances de faroeste, espionagem e pornografia escritos por israelenses circularam como traduções porque seus autores temiam que tais temas e estilos fossem 
considerados impróprios pelos membros dessa nação jovem, sequiosa de formar uma sociedade justa, igualitária e digna. As falsas traduções contribuíram para o surgimento desses modelos, que passaram a ser consumidos no país (p. 43).

Também não se pode omitir a questão político-ideológica na hora de se analisar as pseudotraduções. Quando há grandes forças políticas e ideológicas em jogo, traduções fictícias muitas vezes servem para o autor/editor se proteger de órgãos de censura, sobretudo numa ditadura. Censores tendem a ser mais tolerantes com textos traduzidos, visto que produções estrangeiras parecem menos ameaçadoras do que algo redigido pela intelectualidade local. Por outro lado, falsas traduções também podem se prestar à imposição de normas de conduta e circulação de idéias num estado totalitário. Em seu livro de memórias, o compositor russo Dimitri Shostakovitch oferece um exemplo interessante, relatado por Toury (1995: 43-44), desse tipo de estratégia na época em que Stalin dirigia a União Soviética. Segundo Shostakovitch, o governo stanilista utilizou pseudotraduções para enaltecer o grande líder e suas realizações, bem como fazer com que os “novos escravos”, no caso a república soviética do Cazaquistão, exibissem suas realizações culturais aos residentes da capital. As ditas traduções eram poemas patrióticos produzidos por poetas recrutados pelo estado, mas falsamente atribuídos a um cantor folclórico cazaque chamado Dzambul Dzabayev. O artista de fato existia; no entanto, parecia não ter conhecimento da farsa montada, pois simplesmente assinava um contrato atrás do outro, confiante de que estava recebendo dinheiro apenas pela sua assinatura. O embuste envolvendo o artista durou até sua morte, mas, de acordo com Shostakovitch, estratagemas semelhantes foram empregados na música e em outras formas de manifestação artística como parte de uma operação maior de planejamento cultural.

Apesar de todos os casos relatados até aqui podem ser facilmente definidos como pseudotraduções, categorizar uma obra como tal nem sempre é tarefa tão simples, visto que determinados textos são apresentados de uma forma pelos autores e interpretados de outra pelos leitores. A Living Bible (versão inglesa da Bíblia lançada em 1971), por exemplo, chegou ao público como uma paráfrase em inglês do livro sagrado e não como tradução. No prefácio, seus autores explicam que não haviam consultado os textos originais em hebraico, aramaico e grego, apenas trabalhado com as traduções existentes em inglês, pois pretendiam tornar a mensagem bíblica mais acessível ao leitor por meio de uma linguagem moderna. Apesar disso, a Living Bible costuma ser lida como tradução, visto que o termo paráfrase não impede sua 
categorização como tal. Além disso, a terminologia adotada por Roman Jakobson permitiria classificá-la como uma tradução intralingual. Fica então a dúvida, a Living Bible seria uma pseudotradução ou não (Robinson, 1998: 183)?

Outra obra de cunho religioso que suscita certa controvérsia quando rotulada de pseudotradução é O livro de mórmon (1830). O texto foi apresentado como uma tradução e contribuiu para o surgimento de uma nova religião na cultura cristã estadunidense, a Igreja de Jesus Cristo dos Santos dos Últimos Dias. De acordo com seu fundador, Joseph Smith, um anjo guiou-o até o local onde havia placas douradas com inscrições em egípcio antigo (língua que ele não conhecia) e ajudou-o a traduzir o conteúdo para o inglês. Muitos seguidores dessa fé acreditam nessa história, mas, segundo o teórico americano Douglas Robinson, se O livro de Mórmon não for considerado pseudotradução, será preciso reconhecê-lo como um dos maiores exemplos de uma tradução canalizada espiritualmente: “Ao contrário da Bíblia Sagrada, O livro de Mórmon não apresenta um texto-fonte, pelo menos nenhum em circulação humana” (Robinson, apud Filgueiras, 2002: 112).

No capítulo 2, "When a translation is not a translation”, do livro Constructing cultures: essays on literary translation, Susan Bassnett defende um conceito mais elástico para o termo “pseudotradução” do que o sugerido por Toury, calcado apenas na inexistência ou desconhecimento de um original autêntico. Para Bassnett, tal denominação serviria para qualificar textos que não constituem exemplos claros de traduções, como Morte Darthur, de Thomas Mallory (1485). Conforme consta no prefácio, essa obra foi inspirada num conjunto disperso de textos em francês, galês e inglês. Trata-se, portanto, de uma reescrita. Mallory apagou os vestígios que poderiam levar às fontes originais, mas os leitores aceitaram isso, sem reclamar, visto que estavam mais interessados no desenrolar da trama do que em qualquer outra coisa. Fica, porém, a dúvida se a Morte Darthur poderia ser classificada de tradução, pois, embora essa obra pressuponha a existência de um original, este não se restringiria a um único texto e sim a vasto material em diversas línguas.

De acordo com Bassnett, a autotradução também pode se enquadrar na categoria de pseudotradução em determinadas situações. Diante das significativas diferenças encontradas entre o texto inicial em alemão de Quatre poèmes (1961), de Samuel Beckett, e a versão para o inglês feita pelo próprio autor, por exemplo, seria legítimo negar a existência de um original e uma tradução. Melhor seria afirmar que existem duas versões do mesmo texto, escritos pela mesma pessoa, em línguas diferentes. 
As considerações da teórica inglesa abrangem outros casos. Bassnett qualifica como pseudotradução diálogos de relatos de viagem no qual há uso de pidgin English (inglês simplificado para efeito de comunicação entre pessoas de línguas diferentes), para acentuar o estrangeirismo do falante. Tal expediente pode ser observado em The road to Oxiana (1937). Trata-se de uma obra sobre a busca da antiga arquitetura islâmica na Pérsia e no Afeganistão, na qual seu autor, Robert Byron, lança mão de todo tipo de estratégia para indicar que as falas dos personagens foram traduzidas. Embora relatos de viagem não sejam romances e a autenticidade desempenhe papel fundamental para sua aceitação, Bassnett sustenta que, como alguns diálogos são visivelmente inventados, essa exigência desaparece. Autor e leitor aceitam participar desse jogo de faz-de-conta, ou de collusion, segundo a estudiosa. Para ela, o uso de diálogos numa linguagem “pseudomedieval” para induzir o leitor a crer que tais trechos foram traduzidos, conforme Rider Haggard fez em Allan Quatermaine, também constitui uma pseudotradução.

Provavelmente, o único caso relatado por Bassnett com o qual Gideon Toury concordaria de imediato em rotular de pseudotradução seria o de The Kasidah of Hají Abdú El-Yezdí (1924), visto que se trata de uma tradução inventada. Seu autor, o explorador e antropólogo Richard Burton, publicou esse poema como se fosse a obra traduzida por um certo Bernard Quaritch. Burton talvez tenha recorrido a esse expediente porque não queria ver seu trabalho comparado ao Rubaiyat de Edward FitzGerald, que utilizava estilo e temática semelhantes, mas era visivelmente superior. O motivo que pareceu mais plausível para Bassnett, porém, era que a obra precisava ser recebida como tradução, pois, do contrário, não teria lugar no sistema literário inglês: "Ele [Burton] precisava fingir que era outra pessoa que não o criador do texto, a fim de apresentá-lo da forma que desejava” (Bassnett, 1998: 33).

Algumas obras literárias, sobretudo romances, utilizam traduções fictícias como extensão do “manuscrito encontrado”, um artifício bem comum entre escritores. Como muitos romancistas procuram criar histórias que pareçam críveis aos olhos do leitor, lançam mão de uma gama de recursos literários para dar à narrativa aparência de realidade, entre as quais estão o relato em primeira pessoa, a forma epistolar, a reportagem e, claro, o manuscrito descoberto após anos e anos oculto. A fenomenal obra de Miguel de Cervantes, Don Quijote de la Mancha (1605, 1615), por exemplo, afirma que a história que se segue é uma tradução para o espanhol de um antigo manuscrito de autoria do árabe Cide Hamete Benegeli (Robinson, 1998: 185): 
Quando eu ouvi dizer "Dulcinéia do Toboso", fiquei atônito e pasmo, porque logo se me afigurou que aqueles cartapácios continham a história de D. Quixote. Com esta imaginação, apressei-o a que lesse o princípio, e, fazendo-o assim, vertendo de improviso o árabe para castelhano, disse que dizia: História de D. Quixote da Mancha, escrita por Cide Hamete Benegeli, historiador árabe. Muita discrição foi mister para disfarçar o contentamento em que fiquei quando chegou a meus ouvidos o título do livro, e, adiantando-me ao mercador, comprei do rapaz todos os papéis e cartapácios por 107 meio real; enquanto, se ele tivesse perspicácia e soubesse quanto eu os desejava, bem poderia ter pedido e levado mais de seis reais de compra. Apartei-me logo com o mourisco pelo claustro da igreja matriz, e pedi-lhe me vertesse aqueles cartapácios, todos os quais tratavam de D. Quixote, para a língua castelhana, sem tirar-lhes nada, oferecendo-lhe o pagamento que quisesse. Contentou-se com duas arrobas de passas e duas fanegas de trigo, e prometeu traduzi-los bem e fielmente e com muita brevidade. Mas eu, por facilitar mais o negócio e por não dar de mão a tão bom achado, levei-o para minha casa, onde em pouco mais de mês e meio a traduziu toda, do modo mesmo como aqui se refere. (Cervantes, 2005: 107)

É provável que poucos autores tenham recorrido tanto a trapaças ficcionais como o argentino Jorge Luis Borges. Em boa parte de sua obra, Borges forja escritos apócrifos atribuídos a autores reais ou fictícios, citações existentes atribuídas a autores falsos e traduções que são na verdade invenções, além de utilizar autores reais, como Bioy Casares e ele próprio, como personagens de histórias fantásticas e de apresentar contos como se fossem ensaios ou resenhas de livros. Ao fazer uso de todos esses artifícios, Borges "fundou uma outra concepção de literatura, de autor, de tradução e de leitor para a contemporaneidade, fazendo da leitura um exercício de ficcionalização da paternidade literária, de conversão do autor em criação do próprio leitor” (Maciel, 2002).

As considerações de Bassnett sobre pseudotradução são instigantes. Entretanto, talvez confiram ao termo uma generalização excessiva, que permita abarcar uma diversidade de casos e acabe por roubar espaço daqueles que seriam exemplos incontestáveis de pseudotradução, na perspectiva mais rígida de Toury. A história registra algumas situações evidentes desse fenômeno, dentre as quais despontam as "traduções" feitas pelo escocês James Macpherson de obra poética de Ossian: Fragments of ancient poetry translated from the Gaelic or Erse language (1760), Fingal (1762) e Temora (1763). Ossian era o nome anglicizado (e popularizado por Macpherson) de Oisín, um lendário guerreiro e poeta irlandês do século III. Pouco após amargar a indiferença da crítica por sua obra The highlander (1758), Macpherson debruçou-se sobre manuscritos e poemas orais gaélicos, a fim de compor poemas e apresentá-los como traduções desse poeta medieval. Na época, não se sabia que inexistem manuscritos gaélicos anteriores ao século $\mathrm{X}$. A fraude só foi descoberta no 
final do século XIX, quando se constatou que os ditos poemas originais usados por Macpherson - e publicados após sua morte - eram, na verdade, toscas traduções feitas pelo próprio Macpherson do inglês para o gaélico (Robinson, 1998: 183-4).

Em sua dissertação de mestrado, Ofir Bergemann de Aguiar explica que foram realizados estudos por meio dos quais se percebeu que o conteúdo do material macphersoniano não repousava em nenhum poema autêntico: “O escritor teria se aproveitado de alguns nomes e cores, expressões e fatos, inventando um poema sentimental e atribuindo-o ao bardo antigo” (1999: 22). A pesquisadora explica que a descoberta da não-autenticidade dos poemas de Macpherson levou ao declínio da voga ossiânica, visto que grande parte do seu sucesso se devia ao interesse despertado por eles como documento histórico. Por esse motivo, continua Aguiar, James Macpherson passou para a história como falsário e impostor (p. 22).

A ironia por trás desse caso é que, apesar da origem forjada, os poemas de Ossian tiveram enorme impacto sobre poetas e pensadores no Reino Unido, Alemanha e em vários outros lugares, inclusive no Brasil. Muitos viram neles uma autêntica manifestação do espírito folclórico primitivo. Os poemas se tornaram um sinalizador do movimento que culminaria no romantismo, sendo vistos como prova de que a grandeza literária não precisava decorrer apenas de civilizações avançadas, camadas sociais mais cultas ou modelos clássicos consagrados. Poderia também emergir da imaginação do homem comum, do camponês. Como os românticos tinham interesse na autenticidade desses poemas, mostravam-se propensos a acreditar neles (Robinson, 1998: 184).

Pode-se especular sobre os motivos que teriam levado Macpherson a empreender tamanha farsa. Talvez ele estivesse magoado com o descaso da crítica literária da época e desejasse zombar dela pregando-lhe uma peça. O escritor deve ter percebido que o momento era propício para o lançamento poemas narrativos medievais. Afinal, ao contrário dos povos mediterrâneos que podiam se gabar das obras de Homero e Virgílio, os do norte da Europa — germânicos, anglo-saxões e escandinavos — não dispunham de uma grande literatura épica para celebrar. Os supostos escritos de Ossian supriram essa carência com maestria e renderam reconhecimento a Macpherson em vida.

Outro episódio claro de pseudotradução ocorreu em 1894, quando o poeta Pierre Louÿs lançou uma coleção de poemas lésbicos — Les chansons de Bilitis - como se fosse a obra de uma poetisa grega, contemporânea de Safo, chamada Bilitis. Em vez de assumir a autoria, Pierre Louÿs apresentou-se como mero tradutor dos 143 poemas em 
hexâmetros vertidos em prosa poética - como era de praxe se fazer na época, na França, no caso de tradução de poesia - e escreveu um prefácio que contava um pouco da história da suposta escritora. A fraude não tardou a ser desmascarada; no entanto, a descoberta não impediu que os versos de Les chansons causassem profundo impacto nos leitores pelo estilo refinado e elevado grau de sensualidade e erotismo. Claude Debussy, um grande amigo de Pierre Louÿs, chegou a musicar partes do livro. Em 1955, uma das primeiras organizações lésbicas dos Estados Unidos intitulou-se as Filhas de Bilitis. E, ainda hoje, os poemas são amplamente difundidos e venerados como exaltações ao amor entre mulheres por escritoras homossexuais (Venuti, 2002: 70-72).

Em Descriptive Translation Studies and beyond, Toury narra um caso incontestável de pseudotradução ocorrido na Alemanha, no século XIX: a publicação de Papa Hamlet (1889) como de autoria de Bjarne Peter Holmsen. O livro constituiria a primeira parte de uma trilogia de prosa poética, escrito por um jovem autor norueguês, praticamente desconhecido na sua própria terra, e traduzido para o alemão por Bruno Franzius, doutor em literatura. Papa Hamlet continha o nome do tradutor na capa e um prefácio assinado por ele, como era costume na época. Nesse prefácio o leitor encontrava um esboço biográfico do autor e um relato das dificuldades enfrentadas pelo tradutor ao verter a obra para o alemão, além de justificativas para as escolhas que ele havia feito. Nenhum dos resenhistas alemães tinha ouvido falar em Holmsen e todas as informações que recolheram foram retiradas do prefácio do tradutor, cujo título de doutor aparentemente reforçara a confiança nele como fonte.

Alguns meses depois, surgiram provas incontestáveis da farsa. As três histórias eram produto do esforço conjunto de Arno Holz e Johannes Schlaf, que também forjaram todo o resto, inclusive uma foto do suposto autor. Tratava-se de um primo falecido de um dos dois. O livro continuou a circular após a descoberta do segredo, mas acrescido dos nomes dos dois autores e de toda a série de resenhas publicadas anteriormente. A história envolvendo a obra tornou-se até um chamariz de vendas.

Mas por que a dupla armou essa farsa? Segundo Toury, Holz e Schlaf agiram assim porque desejavam se libertar das amarras do naturalismo francês que dominava a literatura alemã naquele período sem sofrer represálias ou críticas. Resolveram fazer isso por meio da adoção de determinadas normas e modelos da literatura escandinava contemporânea, considerada um tipo de naturalismo diferente. A literatura escandinava gozava de grande popularidade e prestígio na Alemanha naquela época. Logo, Holz e Schlaf acharam que poderiam introduzir novidades na literatura alemã por meio de uma 
pseudotradução. Na época em que os dois se dedicavam à redação de Papa Hamlet, a literatura alemã se mostrava refratária a novas tendências.

Ao comporem a farsa, Holz e Schlaf encheram a obra de características associadas à cultura escandinava. Essas marcas não foram extraídas de obras escritas em norueguês, sueco ou dinamarquês, mas de traduções de obras desses países. Os dois pinçaram elementos lingüísticos, textuais e literários comuns às traduções alemãs de textos naturalistas provenientes da Escandinávia. Eram características com as quais os alemães haviam passado a associar, corretamente ou não, à cultura escandinava. Papa Hamlet de fato foi responsável pela introdução de novidades na literatura alemã. Na verdade, foi um dos precursores do konsequenter Naturallismus, naturalismo alemão inspirado em modelos escandinavos.

Em Portugal, a pesquisadora Maria Lin de Sousa Moniz classificou de pseudotradução os seis volumes da série de narrativas da coleção "Dramas da espionagem”, publicados entre 1932/33 e 1935 como obra de um suposto autor francês chamado George Lody e apresentados aos leitores portugueses como uma "versão livre" de João Amaral Júnior. O referido tradutor era não apenas um profissional respeitado na área como também um escritor de renome. Segundo Moniz, Amaral Júnior teria utilizado esse “disfarce” pelas seguintes razões: 1) o patriotismo vivido antes da Primeira Guerra estava cedendo lugar para a amargura e o desencanto que se refletiam na produção de textos da época; 2) o público demonstrava maior interesse sobre segredos da guerra e práticas de espionagem; 3) o regime fascista em Portugal encontrava-se consolidado naquele momento e exercia forte censura contra tudo que envolvesse a temática comunista (o enredo dessas pseudotraduções se desenrola na Rússia); 4) alguns autores portugueses da época mais tarde confessaram que, no começo da carreira, publicavam textos de sua autoria como traduções porque assim tornavam o produto mais viável comercialmente; 5) Amaral Júnior nunca havia se aventurado nesse gênero e não sabia como seus leitores iriam reagir, nem se produziria algo apreciável (caso a aventura se revelasse um desastre, poderia sempre se esconder atrás da máscara da tradução). De acordo com a estudiosa, após a publicação das pseudotraduções de Amaral Júnior, houve em Portugal um verdadeiro boom da literatura de espionagem, aventura e policial, apesar de qualificada por alguns críticos de "subliteratura” (Moniz, 2005: 8).

No Brasil, os contos policiais que circularam em 1944 como traduções de um suposto autor estrangeiro chamado King Shelter também constituem um caso irrefutável 
de pseudotradução. Tais contos, publicados de junho a dezembro daquele ano na revista Detetive, eram na verdade de autoria da jornalista e escritora Patrícia Galvão, mais conhecida pelo apelido Pagu. O leitor era levado a crer que os textos eram traduções genuínas, visto que apareciam ao lado de obras traduzidas de autores famosos como Agatha Christie, Conan Doyle, entre outros. Esse segredo só foi desvendado por acaso, quase sessenta anos depois, pelo filho de Pagu, Geraldo Galvão Ferraz, quando este fazia uma pesquisa sobre revistas das décadas de 1940 e 1950 nos sebos de São Paulo. Ao se deparar com o nome King Shelter, Geraldo Galvão Ferrz imediatamente lembrouse que esse havia sido um dos pseudônimos usados pela mãe ao longo da carreira de escritora (Galvão Ferraz, 1998: 4). Os nove contos selecionados de um total de doze foram dispostos em ordem cronológica e publicados sob o título de Safra macabra, pela José Olympio, em 1998. A editora preservou integralmente os textos, preocupando-se apenas com a grafia de certas palavras e o aportuguesamento de alguns vocábulos (Grillo, 1998).

Pelo visto, a tentativa de fazer os com que os contos passassem por traduções tinha como objetivo principal assegurar as vendas. Logo, assim como um arguto forada-lei, Patrícia Galvão se disfarçou sob um pseudônimo para que os leitores não descobrissem seu “crime”. Ela se arriscou numa seara literária povoada por autores estrangeiros e na qual nunca produzira coisa alguma e saiu-se muitíssimo bem. A reação calorosa do público com certeza teria sido diferente se soubesse a verdadeira identidade do autor, uma mulher libertária e tida por muitos como polêmica e até imoral por sua defesa do comunismo e idéias feministas. Além disso, a preferência por uma nacionalidade estrangeira revela uma estratégia de marketing, visto que o romance policial nacional era quase inexistente na década de 1940.

No Brasil, a primeira narrativa policial de que se tem notícia foi $O$ mistério. Escrita a oito mãos por Coelho Neto, Afrânio Peixoto, Medeiros e Albuquerque e Viriato Corrêa, a obra chegou ao mercado em capítulos pelo jornal A Folha em 1920. Ou seja, apareceu 79 anos depois do lançamento do conto fundador do gênero, "The murders in the Rue Morgue”, de Edgar Allan Poe, no qual aparece Auguste Dupin, o arquétipo do que viria a ser o detetive moderno: "uma máquina de pensar, que a partir de vestígios, pistas, indícios, consegue, através de uma dedução lógica rigorosa, reconstruir uma história, um fato passado, e assim descobrir o(s) culpado(s)” (Reimão, 2005: 7). Seguindo a cronologia das publicações, $O$ mistério surgiu 33 anos depois da criação do famoso Sherlock Holmes por Arthur Conan Doyle e no mesmo ano do 
lançamento de Hercule Poirot, o detetive idealizado pela “dama do crime” Agatha Christie (Reimão, 2005: 10).

De 1920 até os dias atuais registraram-se incursões brasileiras no gênero policial, porém, a julgar pela cronologia da literatura policial brasileira delineada por Sandra Reimão, o volume da produção até a década de 1970 era relativamente modesto (Reimão, 2005: 10). O cenário só se alterou a partir dos anos 1970, quando Rubem Fonseca despontou com seu estilo hard boiled — uma reação realista à artificialidade do modelo clássico, na qual detetives atormentados por problemas com mulheres, bebidas e falta de dinheiro assumem o lugar dos gênios diletantes da narrativa tradicional. No entanto, a grande mudança no panorama literário se fez sentir na década de 1990, quando o psicanalista e escritor Luiz Alfredo Garcia-Roza apresentou ao público o detetive Espinosa. Antes disso, porém, havia grande número de traduções de romances e contos policiais. Segundo Adriana Pagano, entre as décadas de 1930 e 1950, “o romance policial ou de aventura era o gênero [ficcional] favorito nos mercados brasileiro e argentino. E, curiosamente, esse best-seller foi introduzido principalmente via tradução” (Pagano, 2001: 187). Traduções de histórias policiais eram publicadas na forma de capítulos em revistas de papel jornal (Galvão, 1998: 5). Não seria nenhum absurdo afirmar, portanto, que a as traduções de policiais, incluindo-se aí a pseudotradução de Pagu, teriam preparado o caminho para a consolidação do gênero nacional mais tarde.

Para concluir, poder-se-ia afirmar que o conceito de pseudotradução gera interesse em grande parte porque coloca em xeque a crença tão arraigada de que existe uma diferença fundamental entre original e tradução. No livro Rhetoric, hermeneutics and translation in the Middle Ages (1992), Rita Copeland examina vários textos medievais que se situam numa zona cinzenta entre o que tradicionalmente se entende por obras originais e traduzidas. Tais textos incluem, entre outros exemplos, versões e glosas ampliadas em inglês e francês do Roman de la rose, de Guillaume de Lorris; Legend of good women, de Geoffrey Chaucer; Confessio amantis, de John Gower. Quase todos esses escritos reúnem passagens traduzidas e entremeadas com glosas e comentários que ora são apresentados como tal, ora como traduções e ora como originais. Registros literários dessa natureza mostram o quanto a lei de direitos autorais — que distingue de forma tão contundente obras originais e traduções, bem como autores e tradutores - é uma construção social relativamente recente que possibilitou o surgimento do conceito de pseudotradução. 
Toury (1995) alega que nenhuma pseudotradução conseguiria se situar nos cânones literários dos tempos modernos. Afinal, o mundo assume cada vez mais a aparência da "aldeia global”, preconizada por McLuhan, e as leis de direitos autorais mais rigorosas não permitiriam que tais farsas se mantivessem por muito tempo. Jornalistas se encarregariam de entrevistar o autor, mesmo que por meio de intérpretes; representantes de editoras e críticos literários cotejariam o original com a tradução, e os próprios leitores poderiam exigir informações suplementares sobre o autor. Toda essa movimentação impossibilitaria a manutenção da farsa, principalmente com o apoio da Internet para agilizar o processo.

É fato que os estudiosos de literatura quase sempre trataram as pseudotraduções como meras curiosidades, e renegaram ou ignoraram sua relevância como fenômeno cultural, sobretudo no que tange a seu aspecto histórico e contextual. Pesquisadores da área dos Estudos da Tradução, porém, têm procurado reverter esse quadro, chamando atenção para situações que claramente se enquadrariam na categoria de pseudotradução e para os motivos que levaram seus autores a recorrerem a esse artifício. Com certeza existem casos ainda não desvendados que mereceriam uma investigação. Ou seja, conforme sugere a pesquisadora portuguesa Sousa Moniz (2005), é preciso intensificar os estudos e retirar as "máscaras".

\section{Referências}

AGUIAR, Ofir B. de (1999) Ossian no Brasil. Dissertação de Mestrado, Universidade Federal de Goiânia, Goiânia: Editora UFG.

BASSNETT, Susan (1998) “When is a Translation not a Translation?” Susan Bassnettt \& André Lefevere (eds.) Constructing cultures: essays on literary translation. Topics in Translation: 11, 25-39. Clevedon/Bristol: Multilingual Matters.

CERVANTES SAAVEDRA, Miguel (2004 [1605]) Vol. 1, Segunda Parte, Capítulo 9: 87. Edição e notas de Francisco Rico (Edición del IV Centenario). Madrid: Santillana Ediciones Generales / Real Academia Española. Também disponível em

http://www.cervantesvirtual.com/servlet/SirveObras/cerv/0581944100051495186 9079/p0000004.htm\#I_20_. Acesso em 13 de junho de 2006.

(2005) O engenhoso fidalgo D. Quixote da Mancha. Trad. de Carlos Nougué e José Luis Sánchez. Rio de Janeiro/São Paulo: Record. 
FILGUEIRAS, Lílian (2002) A invenção do original via tradução, pseudotradução e auto-tradução. Tese de doutorado inédita, USP.

GALVÃO FERRAZ, Geraldo (1998) “Introdução”. Em Safra macabra. Rio de Janeiro: Editora José Olympio.

GRILLO, C. (1998) “King Shelter também tinha seu Sherlock”. Folha de S. Paulo. 24 de abril de 1998.

MACIEL, M. E. (2002) "Exercícios de ficção: Peter Greenaway à luz de Jorge Luis Borges”. Revista de Cultura $\mathrm{n}^{0} 23$ - Fortaleza, São Paulo. http://www.revista.agulha.nom.br/ag23greenaway.htm. Acesso em 28 de maio de 2006.

MONIZ, Maria Lin de S. (2005) “A case of pseudotranslation in the Portuguese literary system”. Trabalho apresentado na Conferência Internacional “Translating and Interpreting as a Social Practice” - Graz, 5-7 de maio de 2005.

PAGANO, Adriana S. (2001) “An item called books: translations and publishers.

Collections in the editorial booms in Argentina and Brazil from 1930 to 1950”.

John Milton (org.) Emerging views on translation history in Brazil - Crop 6, 171194.

REIMÃO, Sandra (2005) Literatura policial brasileira. Rio de Janeiro: Zahar.

ROBINSON, Douglas (1988) “Pseudotranslation”. Mona Baker (ed.) Encyclopedia of Translation Studies, 183-185. London/New York: Routledge.

SHUTTLEWORTH, Mark \& COWIE, Moira (1997) “Pseudotranslation”. Dictionary of Translation Studies, 38-39; 127-129; 134-135. Manchester, UK: St. Jerome Publishing.

TOURY, Gideon (1995) Descriptive Translation Studies and beyond. Amsterdam/Philadelphia: John Benjamins.

VENUTI, Lawrence (2002). Escândalos da tradução: por uma ética da diferença. Trad. Laureano Pelegrin, Lucinéia Marcelino Villela, Marileide Dias Esqueda, e Valéria Biondo. Bauru, SP: EDUSC. 